\title{
Effects of Euglycemic Hyperinsulinemia on Neonatal Canine Hepatic and Muscle Metabolism
}

\author{
ROBERT KLIEGMAN, CLEIDE TRINDADE, MARION HUANG, AND SONIA HULMAN
}

Department of Pediatrics, Case Western Reserve University, Rainbow Babies and Children's Hospital, Cleveland, Ohio 44106, and Department of Pediatrics, Faculdade de Medicina de Botucatu UNEP, Sao Paulo, Brazil

\begin{abstract}
The effects of euglycemic hyperinsulinemia on hepatic and muscle metabolism were determined in the fasted newborn dog during the first day of life. Hyperinsulinemia was sustained with a primed constant infusion of insulin whereas euglycemia was maintained with an intravenous infusion of $10 \%$ glucose using the insulin clamp technique. Euglycemic hyperinsulinemia caused an increase of glucose utilization from $43.9 \pm 3.7$ to $66.5 \pm 5.4$ $\mu \mathrm{mol} / \mathrm{kg} / \mathrm{min}(p<0.001)$ and reduced endogenous glucose production to $44.4 \pm 5.4 \%$ of basal values obtained before the induction of hyperinsulinemia. Hepatic tissue glycogen, triglycerides, or intermediates were not altered by hyperinsulinemia nor was the incorporation of $\left[{ }^{3} \mathrm{H}\right]$ glucose into glycogen. However, the hepatic cytoplasmic redox state was more oxidized, and the incorporation of $\left[{ }^{3} \mathrm{H} \mid\right.$ glucose into triglycerides was higher among hyperinsulinemic pups. Pups who demonstrated incomplete suppression of endogenous glucose production had metabolite perturbation suggestive of ongoing gluconeogenesis. Despite very few changes in hepatic tissue metabolite levels, pups subjected to hyperinsulinemia demonstrated a linear uptake of 2deoxyglucose into hepatic tissue as a function of circulating insulin levels during hyperinsulinemia. Muscle tissue demonstrated no alterations of tissue metabolites, glycogen, or triglycerides levels or precursor incorporation into these storage pools. Nonetheless, 2-deoxyglucose incorporation into neonatal muscle tissue was a significant linear function of plasma insulin concentration. Total tissue 2-deoxyglucose uptake was lower in muscle tissue than in hepatic tissue $(245 \pm 19$ versus $514 \pm 20 \mathrm{dpm} / \mathrm{g} / \mathrm{min})(p<0.001)$. These data suggest that hyperinsulinemia has little effect on neonatal net glycogen or triglyceride synthesis but does augment tissue glucose uptake. In newborn liver, part of the insulin-stimulated glucose uptake may be used in futile cycles such as triglyceride synthesis and lipolysis. Furthermore, hyperinsulinemia probably does not suppress hepatic gluconeogenesis as evident by persistent glucose production during the clamp period. (Pediatr Res 25:124129, 1989)
\end{abstract}

\section{Abbreviations}

\author{
2-DG, 2-deoxy| ${ }^{14}$ C|glucose \\ UPD-GIc, uridine diphosphoglucose \\ glucose 6-P, glucose 6-phosphate \\ fructose 6-P, fructose 6-phosphate \\ PEP, phosphoenolpyruvate \\ F 1,6,P, fructose 1,6-diphosphate \\ $\alpha$-KG, $\alpha$-ketoglutarate
}

Received June 6, 1988; accepted September 20, 1988

Correspondence R.M. Kliegman, Department of Pediatrics, Rainbow Babies and Children's Hospital, 2101 Adelbert Road. Cleveland, $\mathrm{OH} 44106$.

Supported by NIH Grant HD 2085
Circulating insulin and glucose concentrations have been proposed to regulate carbohydrate metabolism independently among adult and newborn mammals (1-5). Under varying experimental conditions, hormones or substrates have been demonstrated to regulate the activation-inactivation cycle of the enzymes of hepatic glycogen synthesis and gluconeogenesis. In utero, insulin and glucose or glucose alone have been demonstrated to stimulate the enzymes of glycogen synthesis or to enhance hepatic glycogen content (6-9).

After birth, the mammalian newborn demonstrates poor regulation of blood glucose levels and is also considered to be insulin resistant (10-15). Insulin-mediated effects on hepatic glucose metabolism in the newborn mammal may be attenuated, as evidenced by a reduced suppression of endogenous glucose production in the presence of hyperinsulinemia compared with near complete suppression among adults $(10,14,15)$. Furthermore, insulin-stimulated glucose uptake in insulin sensitive tissues is also attenuated in the newborn compared with the adult mammal $(14,15)$.

In many previous investigations, the effects of hyperinsulinemia on glucose metabolism without concomitant hyperglycemia (as in the fetus of a diabetic mother) or hyperinsulinemia without hypoglycemia were not clearly and independently identified. Hyperglycemia may regulate glucose utilization by modification of enzyme activities or by a mass action effect $(16,17)$. Hypoglycemia may perturb the steady state by stimulation of counterregulatory hormones such as glucagon or epinephrine (17). Presently, little research on the effects of insulin on neonatal tissue metabolism is not confounded by these additional variables. In the present investigation, we used the euglycemic hyperinsulinemic clamp technique to determine the neonatal tissue response to sustained insulin stimulation $(17,18)$. By clamping blood glucose levels constant and at fasting or basal concentration, the action of insulin per se on tissue glucose metabolism can be investigated. The euglycemic hyperinsulinemic clamp can determine the effects of insulin on suppression of endogenous (predominantly hepatic) glucose production and peripheral tissue glucose utilization. In addition to the determinations of the effects of insulin on circulating glucose kinetics, we have investigated the concomitant perturbations by insulin on hepatic and muscle tissue metabolites, fuel storage pools, enzymes, and uptake of glucose by these specific tissues (1). Analysis of hepatic tissue may determine the mechanisms of action of insulin that are responsible for the suppression of endogenous glucose production; muscle tissue analysis may identify the pathways of peripheral tissue glucose utilization.

\section{MATERIALS AND METHODS}

Materials. D-[6- $\left.{ }^{3} \mathrm{H}\right]$ glucose $\left[1-{ }^{14} \mathrm{C}\right]$ palmitate and 2-deoxy $\left[{ }^{14} \mathrm{C}\right]$ glucose were purchased from New England Nuclear Corp. (Boston, MA). All enzymes were purchased from Sigma Chemical Co. (St. Louis, MO). Thin-layer chromatography plates were 
purchased from Eastman-Kodak Co. (Rochester, NY). All chemicals and standards were reagent grade.

Animals. This study was approved by the Case Western Reserve University Animal Welfare Committee. Pregnant beagle dogs were maintained in kennels and fed standard canine diet until 1 day before delivery when they were fasted but had free access to water. Cesarean sections were performed at term gestation after intravenous anesthesia with chlorpromazine $(4 \mathrm{mg} /$ $\mathrm{kg}$ ) and $1 \%$ lidocaine infiltrated in the incision area. After delivery, newborn pups were dried and maintained in incubators at $37^{\circ} \mathrm{C}$ and $70 \%$ humidity. After stabilization, umbilical arterial and venous catheters were placed without trauma or stress and the pups rested in incubators during the remainder of the study $(7,19-21)$.

Euglycemic Hyperinsulinemic Clamp. This technique was used to assess the isolated effects of hyperinsulinemia without the effects of hypoglycemia or hyperglycemia. Background of the clamp method and rationale have been reported previously (14, 17,18 ). A total of 59 euglycemic hyperinsulinemic pups were studied initially, and then 20 more were investigated with the addition of 2-DG to the infusate (see below). To determine glucose turnover and glucose utilization during the clamp, tracer quantities of $\left[6-{ }^{3} \mathrm{H}\right]$ glucose $(4.5 \mu \mathrm{Ci} / \mathrm{kg} / \mathrm{h} ; \mathrm{sp}$ act, $33.9 \mathrm{Ci} / \mathrm{mmol})$ were infused at a constant rate during the entire study, which lasted $195 \mathrm{~min}$ after a priming dose (23). This infusion was begun at $3-6 \mathrm{~h}$ of life in previously fasted pups. After $60 \mathrm{~min}$, a steady state of tracer radioactivity was achieved, and the fasting blood glucose concentration at 90 min was considered the basal level for the clamp study. The euglycemic hyperinsulinemic clamp was initiated as previously described at 90 min of the study (14). Within the context of this method, blood glucose and plasma insulin levels are "clamped" constant with blood glucose levels clamped at basal fasting levels $( \pm 10 \%)$, and plasma insulin levels are maintained at hyperinsulinemic concentrations.

Insulin $(100 \mathrm{U} / \mathrm{ml})$ was diluted in normal saline and infused at a constant rate of either $3.75,7.5,15,30,60$, or $100 \mathrm{mU} / \mathrm{kg} /$ min via the umbilical vein during the subsequent $105 \mathrm{~min}$ of the study. Pups from each litter were randomly assigned to individual insulin infusions. To maintain euglycemia, blood glucose was immediately determined at each 10- to 15- min interval from arterial blood on a Beckman glucose analyzer (Beckman Instruments, Inc., Fullterton, CA), and an exogenous infusion of glucose was adjusted using the negative feedback principle (17, 18). Anyrequirement of exogenous glucose to maintain normal levels of blood glucose during the clamp is a direct reflection of insulin-stimulated tissue glucose uptake. Blood samples were also collected at 75, 90, and 105 min after the beginning of the insulin clamp, when the steady state for the clamp period was reached, to determine plasma insulin concentration and glucose kinetic data. All blood withdrawn was replaced by equivalent volumes of a normal saline solution.

In 20 additional newborn pups, 2-DG was added to the clamp infusate to study "in vivo" glucose uptake by specific tissue in the presence of euglycemia and varying grades of hyperinsulinemia $(1,14,17,21)$. $\left[{ }^{14} \mathrm{C}\right]-2 \mathrm{DG}$ (sp act $282.0 \mathrm{mCi} / \mathrm{mmol}$ ) was infused at a constant rate of $0.1 \mu \mathrm{Ci} / \mathrm{kg} / \mathrm{min}$ during the clamp period. Insulin infusion rates were $3.75,15,30$, or $60 \mathrm{mU} / \mathrm{kg} / \mathrm{min}$. Immediately at the end of the clamp studies, which was after 105 min of sustained hyperinsulinemia, the pups were killed. Samples of liver and muscle from the hindquarter were collected and immediately freeze-clamped, placed in liquid $\mathrm{N}_{2}$, and later stored at $-80^{\circ} \mathrm{C}$ until further analyses of tissue glycolytic intermediates and $2-D G$ radioactivity $(7,21)$. In addition, some pups also received an additional primed constant infusion of $\left[1-{ }^{14} \mathrm{C}\right]$ palmitate during the entire $195 \mathrm{~min}$ of the clamp. Subsequently $\left[1-{ }^{14} \mathrm{C}\right]$ palmitate incorporation into tissue triglycerides was determined as reported previously, to quantitate triglycerides synthesis as a function of plasma insulin concentrations (1).

Control pups $(n=26)$ did not receive insulin but did have fasting levels of glucose turnover quantitated with tracer glucose and tissue intermediates analyzed as described above.
Analyses. The homogenization and extraction of liver and muscle were performed as reported previously $(7,21)$. Glucose, glycogen, UDP-Glc, glucose 6-P, fructose 6-P, F 1,6P, phosphoenolpyruvate, pyruvate, lactate, citrate, $\alpha-\mathrm{KG}$, ATP, alanine, glutamine, glutamate, pyruvate kinase, glycogen synthase, and glycogen phosphorylase were assayed as reported previously (7, 21). Plasma insulin was determined by RIA on aliquots collected before and during the clamp period.

$\left[6-{ }^{3} \mathrm{H}\right]$ Glucose and $2-\mathrm{DG}$ after extraction and neutralization, were separated from other compounds by ion exchange chromatography in analytical grade cation exchange resin AG $50 \mathrm{~W}$ $\mathrm{X} 8$ and analytical grade anion exchange resin AG 1-X8 (BioRad Laboratories, Richmond, CA) and counted in the commercial fluid, Scinti-Verse II (Fisher Scientific Co., Pittsburgh, PA) (22). The measurement of the radioactivity of $\left[{ }^{3} \mathrm{H}\right]$ from glucose $\left[{ }^{14} \mathrm{C}\right]$ from $2-\mathrm{DG}$, and $\left[{ }^{14} \mathrm{C}\right]$ from palmitate in blood and tissues was done after appropriate chromatography and extractions in a Beckman LS7500 liquid scintillation system. The counts were expressed as disintegrations/mass/min with time being the duration of the infusion.

Statistical Analysis. Student's $t$ test was used to compare means between control and euglycemic hyperinsulinemic pups for tissue glucose, its metabolites, and amino acids. The paired $t$ test was used for comparison of counts from 2-DG between liver and muscle in the same animal. Regression analysis was used for the analyses of plasma insulin and the levels of counts from 2-DG in tissue and for the ratio $\mathrm{Cm} / \mathrm{Cp}$. Results are mean $\pm \mathrm{SE}$. Because of many assays from each sample, we were unable to assay each metabolite or enzyme on every pup. The sample size is recorded in each table. Detailed data related to brain metabolism among these pups are presented in another report (22).

\section{RESULTS}

Circulating kinetics. Each pup studied was healthy, pink, and active: control pups not receiving the clamp weighed $272 \pm 30$ g; hyperinsulinemic pups weighed $251 \pm 59 \mathrm{~g}$. Fasting basal glucose concentration among control pups and pups before the clamp were $3.9 \pm 0.53$ and $4.4 \pm 0.37 \mathrm{mM}$, respectively. During the euglycemic clamp, blood glucose levels did not vary from the preclamp basal period and were $4.5 \pm 0.4 \mathrm{mM}$. Basal control and preclamp basal plasma insulin levels were $20 \pm 4.8$ and 16 $\pm 3.8 \mu \mathrm{U} / \mathrm{ml}$; insulin concentrations during hyperinsulinemia were $2890 \pm 464 \mu \mathrm{U} / \mathrm{ml}$ (range 33-14,-330). Fasting steady state rates of glucose utilization among control and experimental pups were $33.2 \pm 3.9$ and $43.9 \pm 3.7 \mu \mathrm{mol} / \mathrm{kg} / \mathrm{min}$, respectively. In the presence of sustained euglycemic hyperinsulinemia, systemic glucose utilization increased 1.5 times basal values to $66.5 \pm 5.4$ $\mu \mathrm{mol} / \mathrm{kg} / \mathrm{min}(p<0.001)$. During sustained hyperinsulinemia, endogenous glucose production was suppressed $44.4 \pm 5.4 \%$. Complete suppression (100\%) of endogenous glucose production was evident within a wide range of plasma insulin concentrations (Fig. 1).

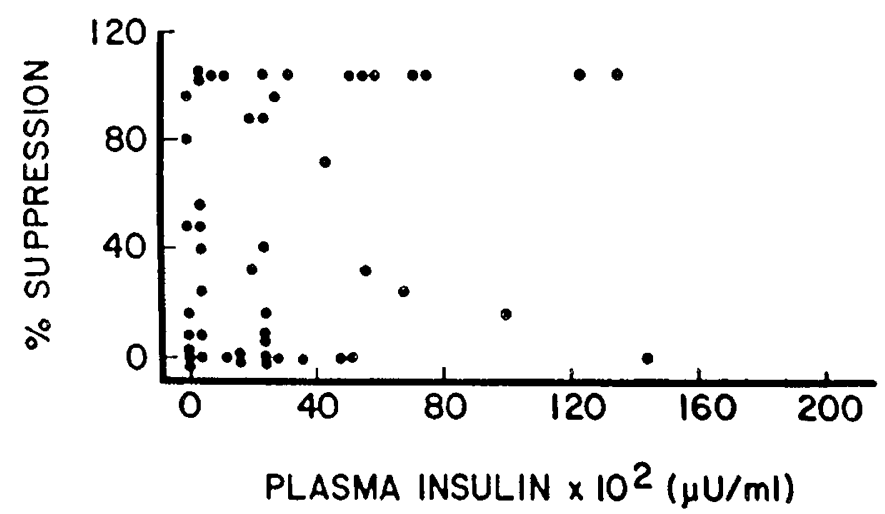

Fig. 1. Percentage suppression of endogenous glucose production as a function of the circulating plasma insulin level during euglycemic hyperinsulinemia. 
Hepatic metabolism. During the euglycemic hyperinsulinemic clamp period, hepatic glucose concentrations were not different than hepatic glucose levels among fasted control pups (Table 1). Despite high plasma insulin concentrations, hepatic glycogen content did not increase above the glycogen content among control pups (Table 1). When analyzed as a function of the achieved plasma insulin concentration, there was no significant relationship between hepatic glycogen concentration and plasma insulin levels $(r=0.149)$. Furthermore, there was no significant relationship between the achieved plasma insulin concentration when compared with the incorporation of label from tracer ${ }^{3} \mathrm{H}$ glucose into glycogen during the clamp period $(r=-0.147)$. In five control and 12 hyperinsulinemic pups, total and glucose 6$\mathrm{P}$-independent glycogen synthase activity were determined. There were no differences in the total $(14.1 \pm 1.2$ versus 12.67 $\pm 0.66)$ and the more active $(4.23 \pm 0.42$ versus $3.54 \pm 0.26$ $\mathrm{nmol} / \mathrm{min} / \mathrm{mg}$ protein) glucose 6 -P-independent enzyme activity between control and hyperinsulinemic pups. Glycogen phosphorylase was also determined in nine control and 10 hyperinsulinemic newborn dogs. There were no differences in active (173 \pm 39 versus $147 \pm 44)$ or total $(202 \pm 22$ versus $232 \pm 67 \mathrm{nmol} /$ $\mathrm{min} / \mathrm{mg}$ protein) hepatic phosphorylase activities among control and hyperinsulinemic pup, respectively.

Additional intermediates of the hepatic glycolytic (glucose 6$\mathrm{P}$, fructose 6-P, F 1,6P, PEP) and Krebs cycle pools (citrate, $\alpha$ $\mathrm{KG}$, glutamate, glutamine, alanine, ammonia) also did not demonstrate significant differences between the two pup groups. Nonetheless, the hepatic cytoplasmic redox state was more reduced in pups during hyperinsulinemia.

When metabolite concentrations of pups were analyzed according to whether there was high $(99.1 \pm 0.7 \%)$ or low $(6.2 \pm$ $3.2 \%$ ) suppression of endogenous glucose production during hyperinsulinemia, both $F 1,6 \mathrm{P}$ and pyruvate levels were increased, whereas fructose 6-P was decreased in pups with complete suppression. This occurred despite similar plasma insulin concentrations and tissue glucose and glycogen levels (Table 2).

Although the static determination of hepatic metabolites did not demonstrate many alterations in the presence of hyperinsulinemia, there was a significant correlation of hepatic 2-DG uptake as a function of plasma insulin concentration (Figs. 2 and 3 ). Both the absolute quantity of $2-D G / U$ time and the partition ratio of hepatic tissue uptake relative to circulating precursor concentration increased in a significant linear relationship as a function of plasma insulin levels.

To further quantitate flux through hepatic metabolic pathways, the incorporation of tracers $\left[{ }^{3} \mathrm{H}\right]$ glucose and $\left[{ }^{14} \mathrm{C}\right]$ palmitate into hepatic triglyceride pools were determined (Table 3 ). $\left[{ }^{3} \mathrm{H}\right]$ from glucose was incorporated into hepatic triglycerides in a significant linear relationship to the plasma insulin concentration. Palmitate incorporation, although linear and positive, was not significantly related to circulating insulin levels. Control pups demonstrated similar mean plasma triglyceride concentrations, as well as similar mean hepatic triglyceride content (Table 4). Thus, despite incorporation of precursor label into hepatic triglycerides, there

Table 1. Hepatic glycolytic intermediates*

\begin{tabular}{lcccc}
\hline \multicolumn{1}{c}{ Intermediate } & $\begin{array}{c}\text { Control } \\
(\text { mean } \pm \mathrm{SE})\end{array}$ & $n$ & $\begin{array}{c}\text { Hyperinsulinemic } \\
(\text { mean } \pm \mathrm{SE})\end{array}$ & $n$ \\
\hline Glucose & $4.02 \pm 0.44$ & 24 & $3.90 \pm 0.31$ & 65 \\
UDP-Glc & $0.096 \pm 0.01$ & 12 & $0.109 \pm 0.02$ & 44 \\
Glycogen & $456 \pm 25.7$ & 22 & $444 \pm 20.4$ & 52 \\
Pyruvate & $0.103 \pm 0.010$ & 23 & $0.084 \pm 0.008$ & 37 \\
Lactate & $2.12 \pm 0.24$ & 23 & $2.59 \pm 0.25$ & 52 \\
ATP & $1.83 \pm 0.17$ & 26 & $1.71 \pm 0.094$ & 70 \\
NAD/NADH & $1654 \pm 605$ & 18 & $557 \pm 106 \dagger$ & 30 \\
\hline
\end{tabular}

* Control plasma insulin $39 \pm 7 \mu \mathrm{U} / \mathrm{ml}$ versus hyperinsulinemic 3053 \pm 479 . Values are in $\mu \mathrm{mol} / \mathrm{g}$ tissue wet wt.

$+p<0.05$
Table 2. Hepatic intermediate values for pups with high and low suppression of endogenous glucose production*

\begin{tabular}{lcrcr}
\hline & $\begin{array}{c}\text { Low } \\
\text { suppression } \\
\text { (mean } \pm \text { SE) }\end{array}$ & \multicolumn{3}{c}{$\begin{array}{c}\text { High } \\
\text { suppression } \\
\text { (mean } \pm \text { SE) }\end{array}$} \\
\hline Plasma insulin & $4928 \pm 1128$ & 14 & $4200 \pm 1049$ & 13 \\
Hepatic glucose & $3.75 \pm 0.63$ & 13 & $3.80 \pm 0.46$ & 12 \\
UDP-Glc & $0.094 \pm 0.017$ & 8 & $0.098 \pm 0.017$ & 12 \\
Glycogen & $407 \pm 32$ & 14 & $467 \pm 57$ & 7 \\
Fructose 6-P & $0.036 \pm 0.002$ & 6 & $0.024 \pm 0.002 \dagger$ & 8 \\
F 1,6,P & $0.027 \pm 0.004$ & 6 & $0.048 \pm 0.007 \dagger$ & 8 \\
PEP & $0.079 \pm 0.011$ & 11 & $0.064 \pm 0.016$ & 10 \\
Pyruvate & $0.073 \pm 0.019$ & 7 & $0.138 \pm 0.018 \dagger$ & 9 \\
Lactate & $2.26 \pm 0.38$ & 12 & $2.37 \pm 0.43$ & 13 \\
Triglyceride & $1.04 \pm 0.25$ & 9 & $0.75 \pm 0.12$ & 12 \\
\hline
\end{tabular}

* High suppression was $99.1 \pm 0.65 \%$; low suppression was $6.2 \pm$ $3.1 \%$.

$$
\dagger p<0.02 \text {. }
$$

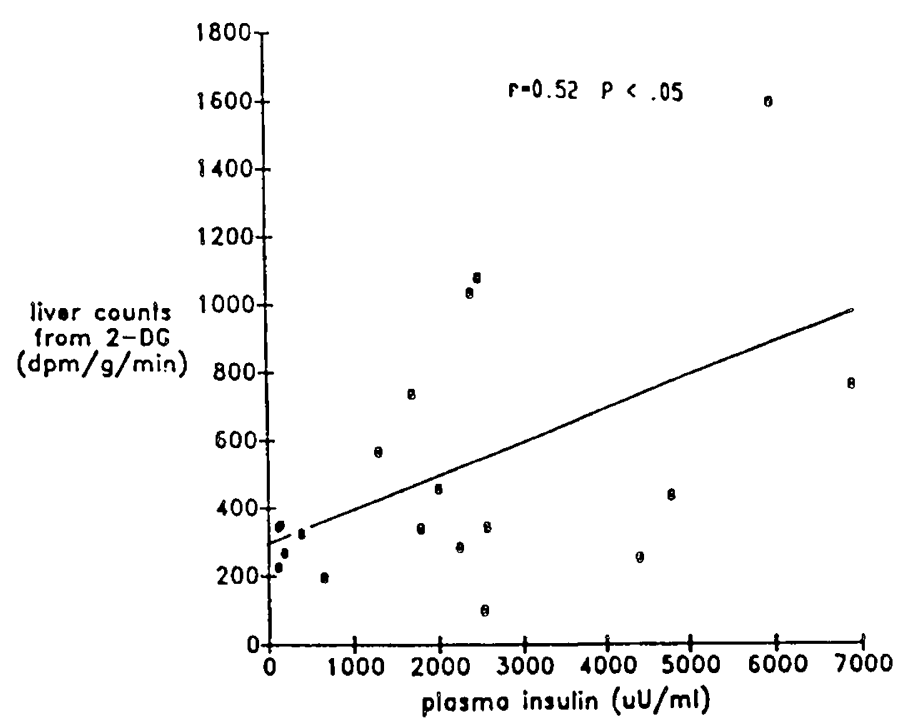

Fig. 2. Absolute liver uptake of a 2-DG as a function of plasma insulin concentrations during euglycemic hyperinsulinemia $(r=0.52, p$ $<0.05)$.

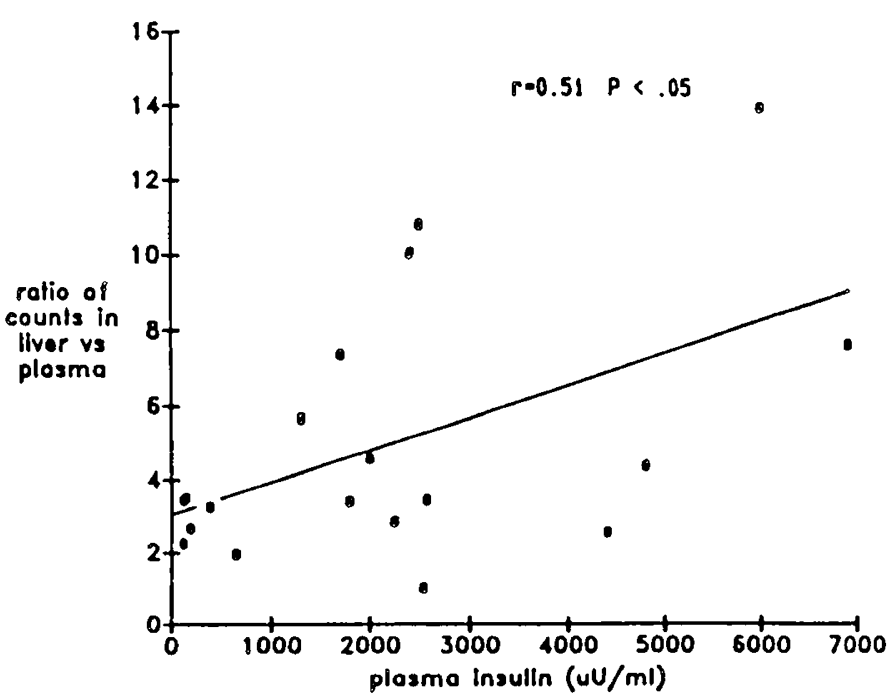

Fig. 3. Ratio of hepatic to plasma 2-DG as a function of plasma insulin concentration during euglycemic hyperinsulinemia $(r=0.51, p$ $<0.05)$. 
was no net hepatic triglyceride synthesis as evidenced by very similar hepatic triglyceride levels in control and hyperinsulinemic pups (Table 4).

Muscle metabolism. In the presence of hyperinsulinemia, there were no significant differences in the levels of the measured glycolytic or Krebs cycle intermediates or amino acids. Nonetheless, the cytoplasmic redox potential was significantly more reduced in hyperinsulinemic pups $(219 \pm 51$ versus $575 \pm 104, p$ $<0.01)$. There was no relationship between $\left[{ }^{3} \mathrm{H}\right]$ glucose tracer incorporation into muscle glycogen when determined as a function of plasma insulin concentration $(r=-0.123)$.

In contrast, 2-DG incorporation into muscle was significantly related to the plasma insulin concentration (Figs. 4 and 5). When determined as 2-DG incorporation/U time or as a ratio depicting greater partitioning of label into muscle at higher insulin concentration, both methods demonstrate significant relationships between 2-DG uptake and plasma insulin concentration. Compared with hepatic tissue, the average rate of 2-DG uptake was significantly lower in muscle tissue $(514 \pm 20$ versus $245 \pm 19$ $\mathrm{dpm} / \mathrm{g} / \mathrm{min}, p<0.01)$. Furthermore, the average partition ratio between tissue and plasma for 2-DG was also higher in liver tissue compared with muscle $(5.02 \pm 0.97$ versus $2.49 \pm 0.84, p$ $<0.05$ ).

Muscle triglyceride content was similar among both pup groups (Table 4). There were no significant relationships between $\left[{ }^{3} \mathrm{H}\right] g l u c o s e$ or $\left[{ }^{14} \mathrm{C}\right]$ palmitate incorporation into muscle triglyceride pools during hyperinsulinemia.

\section{DISCUSSION}

The newborn mammal demonstrates insulin resistance as evidenced by failure to suppress endogenous glucose production and an attenuation of peripheral tissue glucose utilization in response to insulin administration compared with more mature adults $(11,14,15,23-25)$. Because there are ample numbers of cellular insulin receptors, and because the maximum response to hyperinsulinemia is reduced compared with adults, it has been proposed that neonatal insulin resistance is a postreceptor defect $(4,14,15,26,27)$. This may be mediated at the level of the glucose transport mechanism, or it may be due to a differential response to insulin activation of insulin responsive regulatory enzymes. Insulin-mediated regulation of hepatic metabolism can be determined by the degree of suppression of endogenous glucose production. Insulin-mediated tissue glucose uptake can be determined by measuring total body glucose uptake. The euglycemic hyperinsulinemic clamp is a method which can measure

Table 3. Labeling of hepatic triglycerides as function of plasma insulin* concentration

\begin{tabular}{lcc}
\hline Source of label & $r$ value $\dagger$ & $p$ value \\
\hline$\left[{ }^{3} \mathrm{H}\right]$ glucose $\ddagger$ & 0.576 & 0.05 \\
{$\left[{ }^{14} \mathrm{C}\right]$ palmitate $\S$} & 0.458 & 0.10 \\
\hline
\end{tabular}

* Plasma insulin ranged from $140-9500 \mu \mathrm{U} / \mathrm{ml}$.

$\dagger r$ values for respective effects in muscle were 0.04 and 0.15 for ${ }^{3} \mathrm{H}$ and ${ }^{14} \mathrm{C}$ incorporation to muscle triglycerides.

$\ddagger^{3} \mathrm{H}$ counts ranged from $9500-504,000 \mathrm{dpm} / \mu$ mol triglyceride.

$\S{ }^{14} \mathrm{C}$ counts ranged from $9000-560,000 \mathrm{dpm} / \mu$ mol triglyceride.

Table 4. Triglyceride responses to hyperinsulinemia*

\begin{tabular}{lcrcc}
\hline Source & $\begin{array}{c}\text { Control } \\
(\text { mean } \pm \text { SE) }\end{array}$ & $n$ & $\begin{array}{c}\text { Hyperinsulinemia } \\
\text { (mean } \pm \text { SE) }\end{array}$ & $n$ \\
\hline Plasma & $1.51 \pm 0.18$ & 11 & $1.38 \pm 0.11$ & 30 \\
Liver & $0.88 \pm 0.18$ & 18 & $0.83 \pm 0.10$ & 44 \\
Muscle & $0.72 \pm 0.25$ & 9 & $0.66 \pm 0.10$ & 40 \\
\hline
\end{tabular}

* Control plasma insulin $39 \pm 7 \mu \mathrm{U} / \mathrm{ml}$ versus hyperinsulinemia 3053 \pm 479 . Values in $\mu \mathrm{mol} / \mathrm{g}$ tissue wet wt.

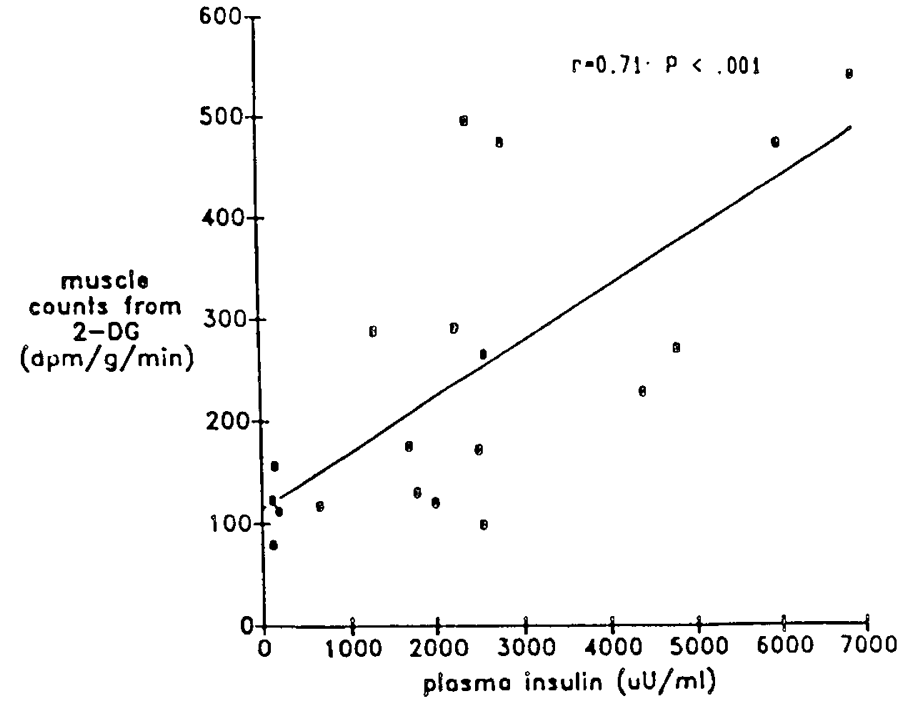

Fig. 4. Absolute muscle uptake of 2-DG as a function of plasma insulin concentrations during euglycemic hyperinsulinemia $(r=0.71, p$ $<0.01)$.

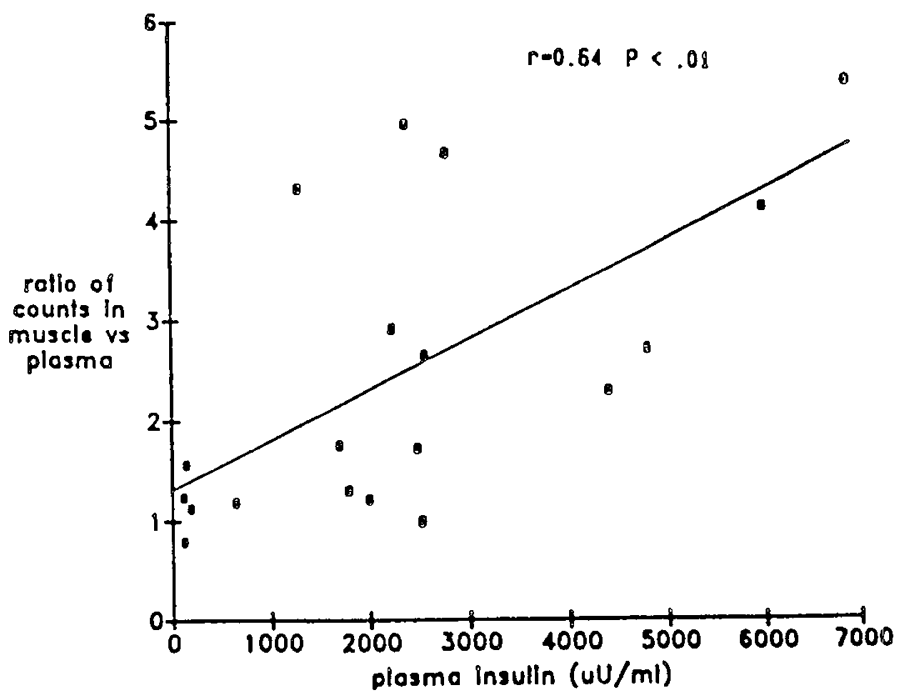

Fig. 5. Ratio of muscle to plasma 2-DG as a function of plasma insulin concentrations during euglycemic hyperinsulinemia $(r=0.64, p$ $<0.01$ ).

insulin's effects on these separate processes independent of substrate (glucose) or counterregulatory hormone effects $(17,18)$.

In the present investigation, we examined the effects of sustained euglycemic hyperinsulinemic on endogenous glucose production, tissue metabolite levels, enzyme activities, and tissue glucose uptake. Sustained hyperinsulinemia resulted in a 1.5fold increase of total body neonatal glucose utilization. Tissue glycogen synthesis may be one major pachway of insulin-stimulated glucose utilization. Insulin has been demonstrated to modulate the reciprocal activities of glycogen synthase and phosphorylase toward net glycogen synthesis in various models (7). Nonetheless, glucose may also produce enzyme activation in concert or independently of ambient insulin concentrations $(6,28)$. In the present investigation, sustained euglycemic hyperinsulinemia had no effect on neonatal hepatic or muscle glycogen metabolism. Hyperinsulinemia did not increase glycogen content or incorporation of tracer glucose into glycogen or alter the enzymes of glycogen synthesis. For both hepatic and muscle tissues, glycogen content was not a function of plasma insulin concentration across a wide range of circulating insulin values. 
Although neonatal tissue glycogen content is elevated during the first day of life, net glycogen synthesis is possible, as is the activation/inactivation of glycogen synthase and phosphorylase $(7,16,19,29)$. In these latter investigations, substrate (glucose or galactose) mediated changes in neonatal canine hepatic glycogen content during the 1 st day of life. These data suggest that the newborn can respond to substrate stimuli which result in enhanced tissue glycogen synthesis. In contrast, hyperinsulinemia did not produce an effect of net glycogen synthesis or labeled precursor incorporation into neonatal tissue glycogen stores. Using the euglycemic hyperinsulinemic clamp, similar observations were reported in the adult rat (5). In this murine model, sustained hyperinsulinemia had no effects of hepatic glycogen stores, nor did insulin effect a change of glycogen synthase or phosphorylase despite complete suppression of endogenous (hepatic) glucose production. Additional studies in adult rats using the euglycemic or hyperglycemic hyperinsulinemic clamp demonstrated a dissociation between the effects of substrate and insulin on muscle and liver $(2,3)$. Hyperinsulinemia alone had a very minor effect on hepatic glycogen metabolism, but it enhanced adult muscle glycogen deposition. In contrast, hyperglycemia and hyperinsulinemia enhanced hepatic glycogen synthesis with no further effects on muscle metabolism. In the neonatal period, it is possible that substrate availability, rather than hormonal regulations, functions as the modulator of hepatic and muscle glycogen synthesis. Insulin resistance in muscle tissue may explain the poor response of neonatal muscle to insulinstimulated glycogen synthesis $(11,25)$.

Another pathway of tissue glucose utilization is the synthesis of tissue triglycerides $(5,30)$. This requires tissue glucose uptake, glycolytic pathway activity with the resultant production of acetyl-CoA, fatty acid synthesis, and subsequent esterification to triglycerides. Previous models of hyperinsulinemia in the hyperglycemia fetus of the canine diabetic mother and the euglycemic hyperinsulinemic fetal rhesus monkey have suggested that insulin augmented the rate of neonatal tissue fat metabolism $(8,9)$.

In the present study, insulin was demonstrated to increase both hepatic and muscle glucose uptake. Tissue 2-DG content after the clamp was a positive function of circulating insulin concentration, which suggested a net uptake of glucose in response to varying levels of hyperinsulinemia (1). Although the averaged glycolytic intermediate concentrations were not altered in response to hyperinsulinemia, this static method may not be sensitive enough to determine fluxes through this pathway. The observation that tissue 2-DG concentrations were increased as a function of plasma insulin levels suggests that glycolytic flux was augmented (1). In addition, the positive linear relationship between $\left[{ }^{3} \mathrm{H}\right]$ glucose precursor incorporation into hepatic triglycerides as a function of plasma insulin concentrations also suggests that glycolytic flux was augmented to provide glycerol-P or acetyl-CoA for triglyceride synthesis. Enhanced glycolytic flux could also produce a more reduced (increased NADH) cytoplasm as noted in hepatic and muscle tissue of hyperinsulinemic pups. Further evidence for augmented glycolysis or inhibited gluconeogenesis during suppression of endogenous glucose production was evident by the increased levels of hepatic $F 1,6, \mathrm{P}$ and pyruvate in pups who demonstrated complete suppression of glucose production.

Net triglyceride production was not demonstrated as evidenced by similar tissue and plasma levels of triglycerides among control and hyperinsulinemic pups. Although net tissue concentrations were not increased compared with control pups, the present data suggest that the turnover of hepatic triglycerides increased in response to insulin as newly synthesized and labeled lipid was present after the period of hyperinsulinemia $(5,30)$. This process may be due to an accelerated fatty acid cycle of synthesis and degradation which may be a futile cycle without net triglyceride synthesis but with considerable energy consumption $(5,30)$. Similar observations of enhanced precursor label incorporation into hepatic triglycerides were noted in the adult rat investigated with the euglycemic hyperinsulinemic clamp (30). Enhanced glycolytic flux is required in both the neonatal canine and adult murine models to explain the positive relationship between ambient insulin concentration and precursor label incorporation into hepatic triglycerides. In the absence of net tissue synthesis as measured in the newborn pups, it is possible that futile cycling of glucose-derived carbons into and out of triglyceride pools is one source of the increased glucose utilization during hyperinsulinemia.

Investigations among adult mammals have demonstrated that insulin suppresses endogenous glucose production (predominantly hepatic) in a dose-dependent manner $(5,14)$. In contrast, insulin-mediated suppression of hepatic glucose production among newborn mammals is incomplete $(14,15,23,24)$. Endogenous glucose production persists in the newborn lamb (24), rhesus monkey $(6)$ and $\operatorname{dog}(14,15,16)$ in the presence of what would be an adequate insulin stimulus among adults. Presently the mechanism of insulin-induced suppression of hepatic glucose production is unknown. It has been hypothesized that insulin redirects flow toward net glycogen synthesis rather than glycogenolysis. Furthermore, insulin suppresses gluconeogenesis by inhibition of key gluconeogenic enzymes while stimulating regulatory glycolytic enzymes, thus changing the liver from a glucose-producing organ to a glucose-utilizing organ (31).

The present investigation demonstrated no effect of sustained euglycemic hyperinsulinemia on neonatal canine hepatic glycogen metabolism. There was no effect of insulin on net glycogen synthesis nor cycling of label into hepatic glycogen. Similar observations have been noted in the adult rat during the euglycemic hyperinsulinemic clamp (5). These data suggest that insulin-stimulated glycogen synthesis is not a major pathway of neonatal hepatic glucose utilization and is not an important mechanism for reducing hepatic glucose production.

Gluconeogenesis is active in the newborn dog and in the 1 st day of life may be responsible for as much as $25-50 \%$ of endogenous fasting glucose production (20). Furthermore, glycogen synthesis from lactate has been "paradoxically" demonstrated in the newborn rat during the transition from the fasted to the fed state (29). These data suggest that the flux through the path of gluconeogenesis may persist during states of increased insulin and glucose availability. Although not directly determined in the present study, it is possible that the persistent glucose production in the presence of hyperinsulinemia is due to unsuppressed gluconeogenesis. Pups who did not suppress endogenous glucose production demonstrated lower hepatic F1,6,P and pyruvate levels compared with pups with complete suppression, despite equivalent plasma insulin concentrations. This pattern of metabolites is consistent with ongoing gluconeogenesis.

In summary, newborn dogs demonstrated no net increase of hepatic or muscle triglyceride or glycogen synthesis during sustained euglycemic hyperinsulinemia. Hepatic glycogen synthesis does not appear to be a mechanism which could be responsible for insulin-mediated suppression of endogenous glucose production. Nonetheless, hepatic glucose uptake and glucose incorporation into hepatic triglyceride pools both demonstrated a positive response to increasing plasma insulin concentrations. Enhanced glycolytic activity and/or futile cycling in triglyceride synthesis may be two mechanisms for insulin-stimulated tissue glucose utilization. Augmented glucose utilization by hepatic tissue may divert glycolytic products toward pathways of glucose utilization rather than production. This may be one possible mechanism for insulin-stimulated suppression of endogenous glucose production. Nonetheless, pups who were more insulin resistant may have unsuppressed gluconeogenesis which contributes to continued endogenous glucose production in the presence of hyperinsulinemia.

Acknowledgment. We appreciate the expert assistance on the manuscript by Karen Toil. 


\section{REFERENCES}

1. Kraegen D, James D, Jenkins, A, Chisholm D 1985 Dose response curves for in vivo insulin sensitivity in individual tissue in rats. Am J Physiol 248 (Endocrin Metab 11):E353-E362

2. Kruszynska YT, Home PD, Alberti KG 1986 In vivo regulation of liver and skeletal muscle glycogen synthase activity by glucose and insulin. Diabetes 35:662-667

3. Kruszynska YT, Home PD, Alberti KG 1987 Insulin insensitivity and skeletal muscle enzyme activities in response to overinsulinization in the rat. Metabolism 36:281-285

4, Sinha M, Miller J, Sperling M. Suchy F. Gangner S 1984 Possible dissociation between insulin binding and insulin action in isolated fetal rat hepatocytes. Diabetes 33:864-871

5. Terrattaz J, Assimacopoulos J, Jeanrenaud B 1986 Inhibition of hepatic glucose production by insulin in vivo in rats: contribution of glycolysis. Am J Physiol 250 (Endocrin Metab 13):E346-35

6. Glinsman W, Eisen J, Lynch A, Chez R 1975 Glucose regulation by isolated near term fetal monkey liver. Pediatr Res 9:600-604

7. Kliegman RM, Miettinen EL 1983 Fetal and neonatal metabolism in the pup of a canine diabetic mother: hepatic intermediary metabolism. Diabetes 32:360-367

8. McCormick KL, Susa JB, Widness JA. Singer DB. Adamsons K. Schwartz R 1979 Chronic hyperinsulinemia in the fetal rhesus monkey: effects on hepatic enzymes active in lipogenesis and carbohydrate metabolism. Diabetes 28:1064-1068

9. Susa JB, McCormick KL, Widness JA, Singer DB, Oh W, Adamsons K, Schwartz. R 1979 Chronic hyperinsulinemia in the fetal rhesus monkey: effects on fetal growth and composition. Diabetes 28:1058-1063

10. Cowett R, Oh W, Pollak A. Schwartz R, Stonestreet B 1979 Glucose disposal of very low birth weight infants: steady state hyperglycemia produced by constant intravenous glucose infusion. Pediatrics 63:389-396

11. Cowett R, Czech M, Susa J, Schwartz R, Oh W 1980 Blunted muscle responsiveness to insulin in the neonatal rat. Metabolism 29:563-567

12. Dweck HS, Cassady G 1974 Glucose intolerance in infants of very low birthweight: I:Incidence of hyperglycemia in infants of birth weights 1,100 grams or less. Pediatrics 53:189-195

13. Goldman S, Hirata $T 1980$ Attenuated response to insulin in very low birthweight infants. Pediatr Res 14:50-53

14. Hulman S, Kliegman R., Heng J, Crouser E 1988 Relationship of substrate level to turnover rate in fasted adult and newborn dogs. Am $\mathrm{J}$ Physiol 254:E137-E143

15. Hulman S, Kliegman R, Heng J, Crouser E, Huang M 1986 Assessment of insulin resistance in newborn beagles with the euglycemic hyper-insulinemic clamp. Pediatr Res 20:189(abstr)

16. Varma S, Nickerson H, Cowan J, Hetenyi S 1973 Homeostatic responses to glucose loading in newborn and young dogs. Metabolism 22:1367-1375

17. DeFronzo R, Tobin J, Andres R 1979 Glucose clamp technique: a method for quantifying insulin secretion and resistance. Am J Physiol 237:E214-E223

18. Kolterman O, Insel J, Saekow M, Olefsky J 1980 Mechanisms of insulin resistance in human obesity: evidence for receptor and post-receptor defects. $\mathrm{J}$ Clin Invest 65:1272-1284

19. Kliegman R, Miettinen EL, Morton S 1983 Potential role of galactokinase in neonatal carbohydrate assimilation. Science 220:302-304

20. Kliegman RM, and Morton S 1987 The metabolic response of the canine neonate to 24 hours of fasting. Metabolism 36:521-526

21. Trindade C, Huang M, Hulman S, Reef S, Kliegman R 1988 The effect of euglycemic hyperinsulinemia on cerebral cortical glucose metabolism in newborn beagles. Pediatr Res 23:474-479

22. Kliegman R, Miettinen EL, Adam PAJ 1981 Fetal and neonatal responses to maternal canine starvation: circulating fuels and neonatal glucose production. Pediatr Res 15:945-951

23. Pollak A, Cowett R, Schwartz R, Oh W 1978 Glucose disposal in low-birthweight infants during steady-state hyperglycemia: effects of exogenous insulin administration. Pediatrics 61:546-549

24. Cowett R, Susa J, Oh W, Schwartz R 1978 Endogenous glucose production during constant glucose infusion in the newborn lamb. Pediatr Res 12:853857

25. Riggs T, Wise H, Motz K 1978 Amino acid transport in diaphragms from newborn rats: evidence for insulin resistance. Am J Physiol 235.E304-E310

26. Miller J, Sinha M, Sperling M, Ganguli S 1986 Insulin stimulates amino acid and lipid metabolism in isolate fetal rat hepatocytes. Pediatr Res 20:609612

27. Neufeld ND, Kaplan SA, Lippe BM 1981 Monocyte insulin receptors in infants of strictly controlled diabetic mothers. J Clin Endocrinol Metab 52:473-476

28. Pines M, Bashan N, Moses S 1976 Glucose effect on glycogen synthetase and phosphorylase in fetal rat liver. FEBS Lett 62:301-303

29. Kunst C, Kliegman R, Trindade C 1987 The glycogen synthesis glucose "paradox" in neonatal murine hepatic glycogen synthesis. Pediatr Res 21 (suppl):343(abstr)

30. Hammond VA, Johnston DG 1987 Substrate cycling between triglyceride and fatty acid in human adipocytes. Metabolism 36:308-313

31. Newgard C, Moore S, Foster D, McGarry J 1984 Efficient hepatic glycogen synthesis in refeeding rats requires continued carbon flow through the gluconeogenic pathyway. J Biol Chem 259:6958-6963 